\title{
JUURNAL.RU
}

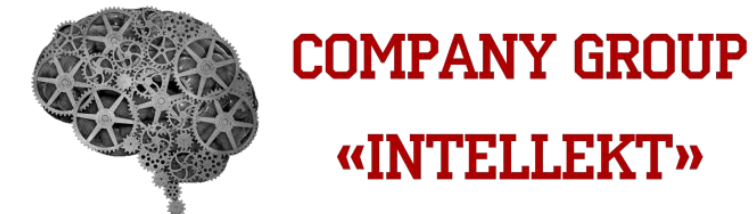

\author{
Чеботарева 3.В., Шибаева А.А. \\ Государственный Университет Управления \\ Москва, Россия
}

doi: 10.18411/lj2016-5-3-20

\section{Роль стратегического управления в менеджменте предприятий на современном этапе развития экономики}

\begin{abstract}
Аннотация
Обозначены основные характеристики стратегического управления, как основы возникновения стратегического управления на предприятиях на современном этапе развития экономики России.

Ключевые слова: Стратегическое управление, экономика, стратегия предприятия

Характеристика современного этапа развития экономики любого государства представляется по качественным изменениям ее структуры, по наличию, полноте и взаимодействию элементов, подчиняющихся нескольким закономерностям.

Ввиду нестабильности рынка, политических, экономических и социальных условий, современные предприятия должны не только следить за состоянием внутренних дел и постановкой операционных целей, но и уметь подстраиваться под внешние изменения, разрабатывая долгосрочную стратегию «выживания». Принимая во внимание данный факт, можно с уверенностью сказать, что благополучие любого предприятия находится в прямой зависимости от качества анализа внешнего окружения и правильного выбора стратегии и целей. Законы экономики порождают динамичность и неопределенность внешних факторов,
\end{abstract}


поэтому ошибки в выборе стратегии предприятия порождают не только потери материальных, денежных, трудовых ресурсов, но и самого невосполнимого ресурса - времени. Если раньше считалось, что крупные корпорации имеют экономические преимущества перед небольшими хозяйствами, то сейчас стало ясно, что преимущество в конкурентной борьбе получает лишь самый быстрый участник данного процесса.

Одним из основных факторов, характеризующих современный этап развития экономики России, является глобализация международной торговли, движения капитала, трудовой миграции, валютно-финансовой сферы.

Следует, заметить, что доказательства позитивного влияния глобализации на поведение и эффективность работы предприятий в основном основаны на данных экономики развитых стран. В развивающихся странах и странах с переходной экономикой ситуация не столь однозначна, а для России эмпирических исследований этих процессов немного. После вступления России во Всемирную Торговую Организацию, предприятия страны, с одной стороны получили возможность стать полноправными участниками мировой торговли, с другой - невозможность прямой конкуренции с иностранными контрагентами ввиду технологического отставания и неготовности экономики. Однако, несмотря ни на что, у российских предприятий появился мотив $\mathrm{\kappa}$ совершенствованию своей продукции, улучшения ее качества и конкурентоспособности. По оценкам экспертов международных и российских организаций, вступление России в ВТО приведет к росту ВВП как минимум на $3 \%$, а также повышению заработной платы и увеличению дохода потребителей [1].

Процессы всеобъемлющей глобализации порождают дальнейшее углубление международного разделения труда. Объективный процесс развития и углубления международного разделения труда идет от общих и частных форм к единичным, при которых осуществляется взаимная кооперация фирм различных стран по совместному производству ими продукции в рамках их 
международной специализации. На этой основе происходит тесное переплетение кругооборотов капитала разных стран и их взаимное технико-экономическое дополнение, называемое экономической интеграцией. $\mathrm{B}$ этой форме национальные хозяйства объединяются в единую систему мирового хозяйства, образуя структурные его части с общей для них экономической инфраструктурой, обеспечивающей развитие между ними товарообмена, свободного перемещения капитала, рабочей силы и оборота информации [2].

Углубление процесса международного разделения труда приводит к тому, что оборот капитала происходит на мировом уровне, начинает оборачиваться капитал не одной национальной экономической системы, а единый мировой капитал, что приводит к ускорению всех экономических процессов и тенденций.

Экономику на современном этапе развития также характеризуют всепоглощающая информатизация. Появление и стремительное развитие интернет-технологий явилось по факту катализатором развития производственных сил, технологического роста. Новые инструменты ускоряют процесс коммуникаций, делают доступ к информации более быстрым. Информация подхлестывает производство, производство требует открытий в области информационных и коммуникационных технологий. Это приводит к сокращению инновационных циклов. Еще 50 лет назад ориентация на инновации являлась достаточным условием лидерства в той или иной отрасли. Сегодня же инновации - необходимое условие выживания.

Данные характеристики современного этапа развития экономики являются основными, но не исчерпывающими. К основным тенденциям развития современной экономики также можно отнести: высокую степень интенсивности мобильности факторов производства, интеграцию капитала и производства, либерализацию внешнеэкономических связей, развитие национальных экономик открытого типа, стремление государств к наднациональному, межгосударственному регулированию валютно-финансовых и экономических процессов. 
Данные факторы обуславливают необходимость обеспечения и сохранения динамичного развития предприятий России в условиях неопределенности и риска путем организации стратегического управленческого учета, ориентированного на сохранение и наращивание потенциала промышленных предприятий Стратегическое развитие становится все более актуальным для российских предприятий и организаций, которые вступают в жесткую конкуренцию, как между собой, так и с иностранными субъектами хозяйственной деятельности.

Стратегическое управление отличается от оперативного управления (Таблица 1) [3].

Таблиия.1

Отличительные черты оперативного и стратегического управления

\begin{tabular}{|c|c|c|}
\hline Критерии отличия & Оперативное управление & Стратегическое управление \\
\hline Миссия & $\begin{array}{c}\text { Производство товаров и услуг с целью } \\
\text { получения дохода от их реализации }\end{array}$ & $\begin{array}{c}\text { Выживание организации в долгосрочной } \\
\text { перспективе посредством установления } \\
\text { динамичного баланса с окружением, } \\
\text { позволяющего решать проблемы } \\
\text { заинтересованных в деятельности } \\
\text { организации лиц }\end{array}$ \\
\hline $\begin{array}{l}\text { Объект изучения } \\
\text { менеджмента }\end{array}$ & $\begin{array}{c}\text { Взгляд внутрь организации, поиск } \\
\text { путей более эффективного } \\
\text { использования ресурсов }\end{array}$ & $\begin{array}{c}\text { Взгляд вовне организации, поиск новых } \\
\text { возможностей в конкурентной борьбе, } \\
\text { отслеживание и адаптация к изменениям в } \\
\text { окружении }\end{array}$ \\
\hline Учет фактора времени & $\begin{array}{c}\text { Ориентация на краткосрочную и } \\
\text { среднесрочную перспективу }\end{array}$ & Ориентация на долгосрочную перспективу \\
\hline $\begin{array}{l}\text { Основа построения } \\
\text { системы управления }\end{array}$ & $\begin{array}{c}\text { Функции и организационные } \\
\text { структуры, процедуры, техника и } \\
\text { технология }\end{array}$ & $\begin{array}{c}\text { Сотрудники, системы информационного } \\
\text { обеспечения, рынок }\end{array}$ \\
\hline $\begin{array}{c}\text { Подход к управлению } \\
\text { персоналом }\end{array}$ & $\begin{array}{c}\text { Взгляд на работников как на ресурс } \\
\text { организации, как на исполнителей } \\
\text { отдельных работ и функций }\end{array}$ & $\begin{array}{c}\text { Взгляд на работников как на основу } \\
\text { организации, ее главную ценность и источник } \\
\text { ее благополучия }\end{array}$ \\
\hline $\begin{array}{l}\text { Эффективность } \\
\text { управления }\end{array}$ & $\begin{array}{c}\text { Прибыльность и рациональность } \\
\text { использования производственного } \\
\text { потенциала }\end{array}$ & $\begin{array}{c}\text { Своевременность и точность реакции } \\
\text { организации на новые запросы рынка и } \\
\text { изменения в зависимости от изменения } \\
\text { окружения }\end{array}$ \\
\hline
\end{tabular}

Вышеуказанные особенности стратегического управления позволяют сформулировать такие понятия как «стратегическое управление» и «стратегия предприятия» 
Стратегическое управление это тип управления, это стратегия выживания в долгосрочной перспективе, достижение целей бизнеса посредством быстрого реагирования управления на новые запросы потребителей, путем достижения конкурентных преимуществ, главным образом, опираясь на человеческий потенциал [3].

Стратегия предприятия, это основанная на стратегическом управлении упорядоченная во времени система приоритетных направлений, форм, методов, средств, правил, приемов использования ресурсного, научно-технического и производственно-сбытового потенциала предприятия в целях экономически эффективного решения поставленных задач и поддержания конкурентного преимущества. [4].

Современная практика ведения бизнеса показывает, что нет стратегии, предприятия, которую можно было бы считать единственно точной для. С одной стороны, также не существует и унифицированного стратегического управления. Каждое предприятие является уникальным. Поэтому процесс разработки стратегии является уникальным и зависит от позиции предприятия на рынке, от динамики развития предприятия, потенциала его развития, от поведения его конкурентов, ассортимента производимой продукции или оказываемой услуги, текущего состояния экономики, культурной среды и многих других факторов.

С другой стороны существует несколько основополагающих моментов, взяв во внимание которые, можно сформулировать основные принципы существования стратегического управления. Стратегическое управление является «творческим» продуктом руководства, владея которым можно более эффективно осуществлять стратегическое управление предприятием.

Разработка стратегии развития предприятия - процедура разработки желаемого состояния организации и конкретных мероприятий по использованию сильных (слабых) сторон для достижения поставленных целей. 
В ходе разработки стратегии развития предприятия определяются следующие аспекты:

1. важность сильных и слабых сторон в деятельности предприятия;

2. вероятность достижения и привлекательность возможностей и угроз;

3. причинно-следственные связи между возможностями, угрозами, сильными и слабыми сторонами;

4. стратегические, среднесрочные и оперативные цели развития компании;

5. показатели, характеризующие цели различных периодов;

6. последовательность и трудоемкость выполнения решений;

7. ответственные исполнители [5].

Стратегическое управление предприятием направлено на поддержание определенных взаимоотношений вышеназванных аспектов с внешней средой путем постановки и реализации целей и задач, соответствующим внутренним возможностям предприятия.

Конечным продуктом стратегического управления предприятием являются:

потенциал, который будет обеспечивать реализацию целей предприятия в будущем;

структура, которая будет обеспечивать чувствительность организации к переменам во внешней и внутренней среде.

Наряду с явными преимуществами стратегического управления, имеется также ряд недостатков и ограничений по его применению.

Во-первых этот тип управления, равно как и все другие, не обладает универсальностью применения в любых ситуациях и для решения любых задач. Стратегическое управление не может дать точной и детальной картины будущего.

Во-вторых, стратегическое управление не может быть сведено к набору унифицированных процессов и схем. Также, стоит отметить, что для 
осуществления стратегического управления требуются огромные усилия и большие затраты времени и ресурсов. Более того, не стоит забывать, что ошибки стратегического планирования крайне негативно влияют на экономическое состояние предприятия.

Таким образом, деятельность руководства предприятия по осуществлению стратегического управления направлена на обеспечение длительной жизнеспособности и развития компании в постоянно изменяющихся условиях рынка. Роль стратегического управления в развитии предприятия велика, потому что только благодаря такому типу управления можно решить на современном этапе развития экономики России основную задачу стратегического управления, состоящую в выявлении необходимости проведения стратегических изменений; в создании соответствующей организационно-управленческой структуры, способствующей положительным стратегическим изменениям; в подборе и развитии человеческих ресурсов, способных провести стратегические изменения в экономике России.

Chebotareva Z., Shibaeva A. State University of Management

The role of strategic management in companies management at the present stage of economic development

Abstract. Outlined the main characteristics of strategic management, as the basis for the emergence of enterprises' strategic management at the present stage of development of the Russian economy.

Keywords. Strategic management, economics, business strategy 


\section{Литература:}

1. АндреевВ. Ф. Системный мир глобальной экономики: филогенези онтогенез: науч. трактат. М., 2013.

2. Виханский О.С. Стратегическое управление: учебник / О.С. Виханский. M., 2010.

3. Велесько Е.И. Стратегическое управление: практика принятия системных решений: учебное пособие / Е.И. Велесько. изд-во БГЭУ, 2003.

4. Томпсон А.А. Стратегический менеджмент: искусство разработки и реализации стратегии: учебник для вузов / А.А. Томсон, А. Дж. Стрикленд. - М.: ЮНИТИ, 1998.

5. http://www.bbc.co.uk/russian/business/2012/08/120821_russia_wto_accession.s html Екатерина Дробинина «Кто в выигрыше от вступления России в BTO?»,2012

6. Чеботарева 3.В., Сотникова Ю.И. Экономическая сущность ликвидности как характеристики финансового состояния экономического субъекта Теоретический и научно-методический журнал «Вестник университета», №3, ГУУ, М:2015 